\title{
Liamocin oil from Aureobasidium pullulans has antibacterial activity with specificity for species of Streptococcus
}

\author{
Kenneth M Bischoff ${ }^{1}$, Timothy D Leathers ${ }^{1}$, Neil PJ Price $^{1}$ and Pennapa Manitchotpisit ${ }^{2}$ \\ The Journal of Antibiotics (2015) 68, 642-645; doi:10.1038/ja.2015.39; published online 15 April 2015
}

Aureobasidium pullulans is a yeast-like fungus that produces a number of industrially useful bioproducts including pullulan, xylanase, lipase and poly $(\beta$-L-malic acid $){ }^{1-3}$ Certain strains produce dense 'oils' that accumulate in liquid cultures. ${ }^{2,4}$ Analysis of A. pullulans oils (subsequently named 'liamocins') identified four types with unique chemical structures consisting of a single mannitol headgroup partially $O$-acylated with polyester tails containing three or four 3,5-dihydroxydecanoic ester groups, some of which may be acetylated (Figure 1). ${ }^{5}$ Although some A. pullulans oils have been observed to exert an antiproliferative effect on certain cancer cell lines, ${ }^{6-7}$ these liamocins had only weak antibacterial activity against Enterococcus faecalis, and no antibacterial activity was observed against Staphylococcus aureus, Lactobacillus fermentum, Escherichia coli or Pseudomonas aeruginosa. ${ }^{7}$

Although over 20 strains of A. pullulans have been shown to produce the heavy oils, ${ }^{4}$ not all have been examined for antibacterial activity. A. pullulans strain NRRL 50380 is one of the best characterized strains with respect to liamocin production, ${ }^{5}$ but its oil has not previously been tested for antibacterial activity. In the present study, we tested oil from strain NRRL 50380 for antibacterial activity against the strains listed above and expanded the pool of target bacteria to include species of Streptococcus. Cultures of A. pullulans were grown in sucrose medium for 7 days at $28^{\circ} \mathrm{C},{ }^{4}$ and liamocins were extracted with 2-butanone as described previously. ${ }^{7}$

Antibacterial activity of NRRL 50380 liamocin oil against selected bacteria was first measured qualitatively by agar diffusion. Bacteria ( $20 \mu \mathrm{l}$ at a density of $0.5 \mathrm{McF}$ arland unit) were spread on tryptic soy agar media, and paper discs $(6 \mathrm{~mm}$ diameter) were placed on the surface. Liamocin oil $\left(10 \mu \mathrm{l}, 50 \mathrm{mg} \mathrm{ml}^{-1}\right.$ in 2-butanone:dimethyl sulfoxide (DMSO) (1:1) solvent) was applied to each disc. Following incubation at $37^{\circ} \mathrm{C}$ overnight, plates were scored for a zone of growth inhibition surrounding the disc. Qualitative analysis found that liamocins have strong antibacterial activity against six of seven Streptococcus species tested: S. agalactiae, S. uberis, S. mutans, S. mitis, S. infantarius and S. salivarius (Table 1). Only S. sobrinus was not susceptible to liamocins. The oil also showed weak activity against E. faecalis, but no activity was observed against $S$. aureus, L. fermentum, E. coli or $P$. aeruginosa (Table 1 ).

MICs of liamocins were determined by a modification of the broth microdilution method. ${ }^{8}$ Serial twofold dilutions of liamocins in 2-butanone:DMSO (1:1) were added to tryptic soy broth (or brain heart infusion broth for E. faecalis) at a final solvent concentration of $1.25 \%$ in the wells of a 96-well plate. Each well was inoculated with the indicated target organism $\left(\sim 10^{5} \mathrm{CFU}\right.$ per $\left.\mathrm{ml}\right)$, and plates were incubated at $37^{\circ} \mathrm{C}$. Plates were scored for the lowest concentration of liamocins that completely inhibited growth of the target strain. Results were consistent with those observed qualitatively, with MICs against Streptococcus species ranging from $\leqslant 10$ to $78 \mu \mathrm{g} \mathrm{ml}^{-1}$, whereas MICs against $S$. aureus, L. fermentum, E. coli and $P$. aeruginosa were greater than $1250 \mu \mathrm{g} \mathrm{ml}^{-1}$, the highest tested concentration (Table 1). For comparison of liamocins potency with traditional antibiotics, we tested the Streptococcus strains for susceptibility to penicillin G, a drug commonly used to treat streptococcal infections. The MIC for penicillin $G$ was $0.12 \mu \mathrm{g} \mathrm{ml}^{-1}$ for all strains except $S$. infantarius NRRL B-41208, which had an MIC of $0.25 \mu \mathrm{g} \mathrm{ml}^{-1}$. Thus, liamocins do not appear to be as potent against streptococci as the broad-spectrum drug penicillin G. Nevertheless, the liamocins' narrow spectrum of antibacterial activity may be advantageous over broadspectrum agents, especially in prophylactic applications to target streptococcal pathogens, but avoid disruption of the beneficial normal flora or selection for antibiotic resistance in commensal bacteria.

Although the data reported here are for liamocins produced by A. pullulans NRRL 50380, oils from the following nine strains of A. pullulans were also tested for antibacterial activity: NRRL 62031, NRRL 62034, NRRL 62038, NRRL 62039, NRRL 62040, NRRL 62041, NRRL 62042, NRRL 50384 and NRRL 50382. In both qualitative antibacterial assays and broth dilution susceptibility tests, liamocins from all strains showed results similar to those observed for liamocins from strain NRRL 50380 (data not shown). Thus, the antibacterial

${ }^{1}$ Renewable Product Technology Research Unit, National Center for Agricultural Utilization Research, Agricultural Research Service, US Department of Agriculture, Peoria, IL, USA and ${ }^{2}$ Biochemistry Unit, Department of Medical Sciences, Faculty of Science, Rangsit University, Lakhok, Patumthani, Thailand

Correspondence: Dr KM Bischoff, Renewable Product Technology Research Unit, National Center for Agricultural Utilization Research, Agricultural Research Service, US Department of Agriculture, 1815 North University Street, Peoria, IL 61604, USA.

E-mail: kenneth.bischoff@ars.usda.gov

Received 14 August 2014; revised 19 December 2014; accepted 5 January 2015; published online 15 April 2015 


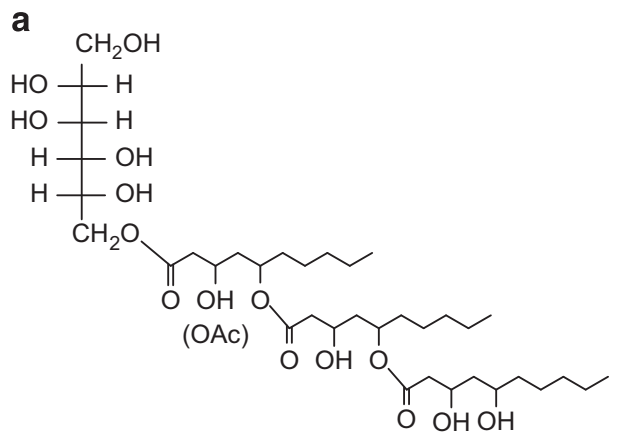

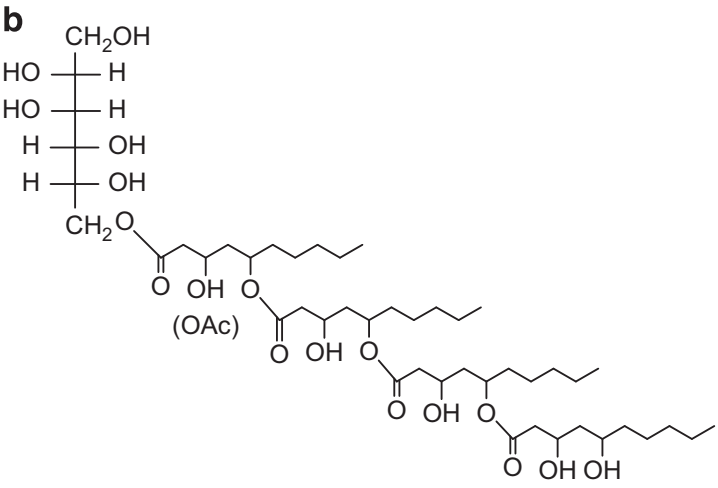

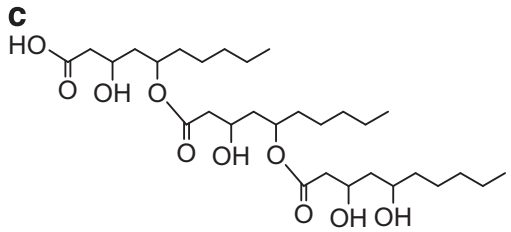

Figure 1 Chemical structures of the liamocins and related exophilins. (a) Liamocin A1 and A2; (b) liamocins B1 and B2; (c) exophilin A. Note that liamocins $\mathrm{A} 2$ and $\mathrm{B} 2$ both contain a 3-O-acetyl (OAc) group.

Table 1 Antimicrobial susceptibility to liamocins produced by A. pullulans strain NRRL 50380

\begin{tabular}{|c|c|c|}
\hline Strain & $M I C^{\mathrm{a}}(\mu \mathrm{g}$ oil per $\mathrm{ml})$ & Qualitative assay ${ }^{b}$ \\
\hline \multicolumn{3}{|l|}{ Streptococcus species } \\
\hline S. agalactiae NRRL B-1815 & 20 & \\
\hline S. uberis & 78 & \\
\hline S. mutans ATCC 25175 & 78 & \\
\hline S. mitis NRRL B-14574 & 20 & \\
\hline S. infantarius NRRL B-41208 & 78 & \\
\hline S. salivarius NRRL B-3714 & $\leqslant 10$ & \\
\hline S. sobrinus NRRL B-4468 & $>1250$ & \\
\hline E. faecalis ATCC 29212 & 312 & \\
\hline S. aureus ATCC 29213 & $>1250$ & \\
\hline L. fermentum 0315-1 & $>1250$ & \\
\hline E. coli ATCC 25922 & $>1250$ & \\
\hline P. aeruginosa ATCC 27853 & $>1250$ & \\
\hline
\end{tabular}

aMICs of liamocin oil from A. pullulans NRRL 50380 were determined by a modification of the broth dilution method, with serial twofold dilutions ranging from 1250 to $10 \mu \mathrm{g} \mathrm{ml}-1$.

${ }^{b}$ Antibacterial activity was measured qualitatively by agar diffusion assay.

${ }^{c} S$. uberis was a gift from David Donovan (USDA-ARS, Beltsville, MD, USA). activity and Streptococcus specificity appear to be a general property of Aureobasidium liamocins.

The solvent extraction process used to prepare liamocins from culture media results in a heterogeneous mixture of liamocin structures $^{5}$ (Figure 1). In an attempt to characterize the antibacterial activity of individual structures, components of A. pullulans NRRL 50380 liamocins were separated by reverse phase chromatography on a Brownlee Spheri 5 RP18 column (Waters Corporation, Milford, MA, USA) (Figure 2a). Fractions were analyzed by matrix-assisted laser desorption/ionization-MS (Figure 2b), ${ }^{5}$ and assayed for antibacterial activity in broth microdilution susceptibility tests. Fractions enriched for liamocin types A1, A2, B1 and B2 had MICs of 64, 128, 16 and $128 \mu \mathrm{g} \mathrm{ml}^{-1}$, respectively. With respect to antibacterial activity, this suggests that liamocin B1, the non-acetylated type with four 3,5dihydroxydecanoic acid (DDA) groups, is the most active type of liamocin.

Viability of $S$. agalactiae following exposure to liamocins was determined by a commercial two-color fluorescence assay (LIVE/ DEAD BacLight Bacterial Viability Assay, Molecular Probes, Eugene, OR, USA) as well as by enumeration of surviving cells on agar media. S. agalactiae was chosen for this assay because it is an important agricultural pathogen, causing mastitis in cattle. Mid-log phase bacteria were suspended in sterile saline to an OD of 0.6 at $600 \mathrm{~nm}$. Cells were treated with varying concentrations of liamocin oil from A. pullulans NRRL 50380 for $1 \mathrm{~h}$ at room temperature. For the fluorescence assay, cells were stained with SYTO 9 and propidium iodide, and fluorescence intensities at $530 \mathrm{~nm}$ (green) and $630 \mathrm{~nm}$ (red) were measured with an excitation wavelength of $485 \mathrm{~nm}$. As specified by the manufacturer, a standard curve plotting the ratio of green:red fluorescence intensities versus percent live cells was constructed by staining bacterial suspensions of varying concentrations of saline-treated cells (live) and isopropanol-treated cells (dead). For enumeration of surviving bacteria, dilutions of treated cells were spread on tryptic soy broth agar plates and incubated at $37^{\circ} \mathrm{C}$.

Treatment of S. agalactiae NRRL B-1815 with 20 and $39 \mu \mathrm{g} \mathrm{ml}{ }^{-1}$ liamocin reduced the percentage of live cells to $50 \%$ and $12 \%$, respectively (Figure 3). Values of percent live cells for the salinetreated and solvent-treated controls were not significantly different 


\section{a}

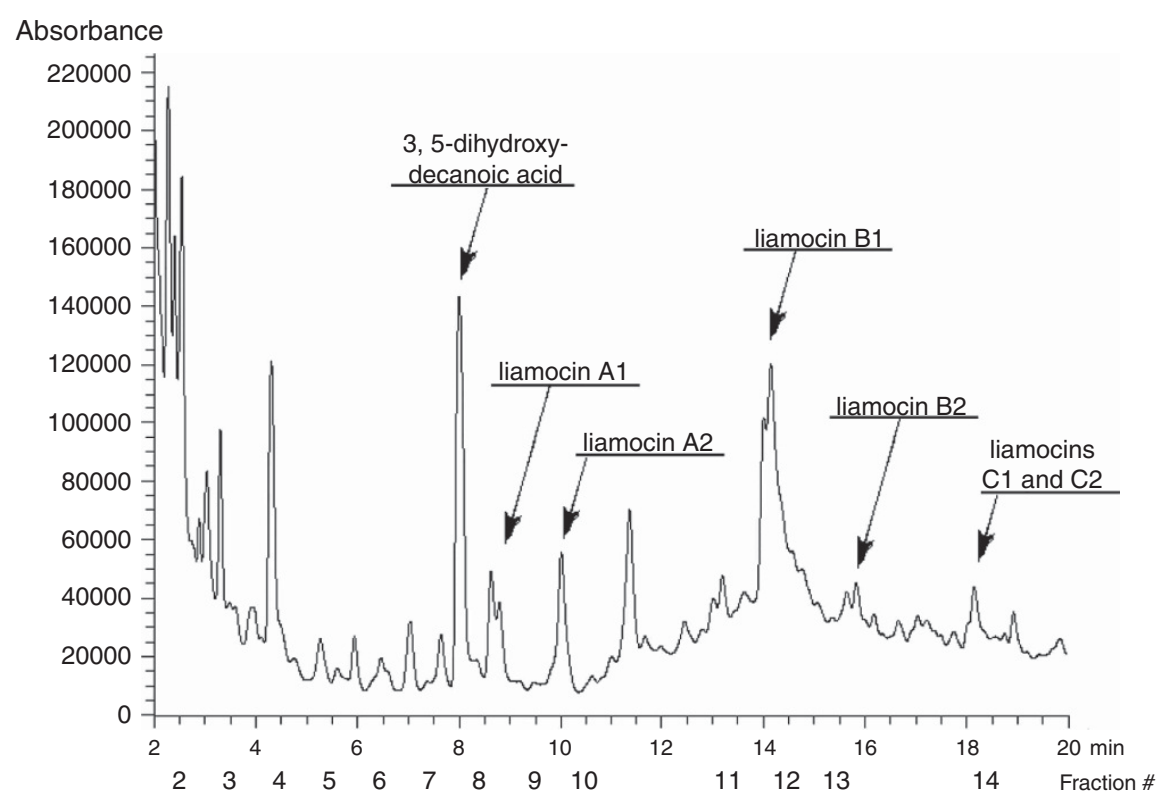

b

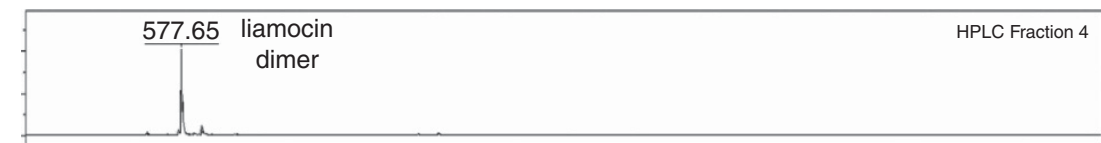

He3.82 liamocin A1 HPC Fraction 8
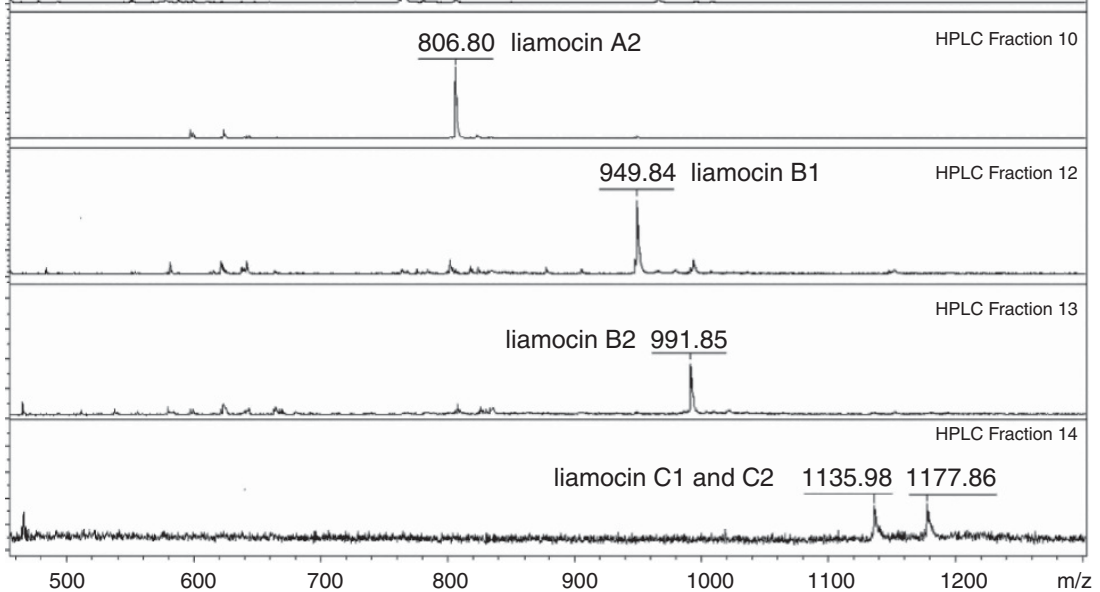

Figure 2 HPLC purification and MALDI MS characterization of component liamocins. (a) Liamocins were fractionated on an RP18 HPLC column using a linear gradient of $50-100 \%$ acetonitrile in water. (b) Fractions collected from the HPLC run were pooled and assayed by MALDI-TOF MS. Molecular adduct ions $\left([\mathrm{M}+\mathrm{Na}]^{+}\right)$are shown for liamocin dimers $(\mathrm{m} / \mathrm{z} 577.65)$; trimers $\mathrm{A} 1(\mathrm{~m} / \mathrm{z} 763.82)$ and $\mathrm{A} 2(\mathrm{~m} / \mathrm{z} 806.80)$; tetramers B1 $(\mathrm{m} / \mathrm{z} 949.84)$ and $\mathrm{B} 2(\mathrm{~m} / \mathrm{z}$ 991.85); and pentamers $\mathrm{C} 1$ ( $\mathrm{m} / \mathrm{z} 1135.98)$ and $\mathrm{C} 2$ ( $\mathrm{m} / \mathrm{z}$ 1177.86). MALDI, matrix-assisted laser desorption/ionization; TOF, time-of-flight.

( $P>0.05)$. Similarly, exposure to $39 \mu \mathrm{g} \mathrm{ml}^{-1}$ liamoncin reduced viable CFUs three log-fold compared with solvent-treated cells $\left(3.4 \log _{10}\right.$ CFU per ml and $6.4 \log _{10}$ CFU per ml, respectively; Figure 3). Higher concentrations reduced viability below $2 \log _{10} \mathrm{CFU}$ per $\mathrm{ml}$. The fluorescence assay is based on the differential labeling of cells with intact and damaged membranes, that is the propidium iodide stain only penetrates cells with damaged membranes. The sudden decrease in the green:red fluorescence ratio following treatment with liamocins suggests a rapid loss of membrane integrity. Taken with the corresponding decrease in recovery of viable cells on tryptic soy broth (TSB) agar plates following exposure, the liamocins appear to be bactericidal for $S$. agalactiae.

The DDA polyester tails of the liamocins are structurally similar to other antimicrobial compounds (Figure 1$).^{5}$ Doshida et al. ${ }^{9}$ reported that exophilin A, a substance produced by Exophiala pisciphila, had antimicrobial activity against E. faecium, E. faecalis and S. aureus, but it did not inhibit growth of Streptococcus epidermis (it should be noted that Exophiala pisciphila has since been reclassified as a strain of 


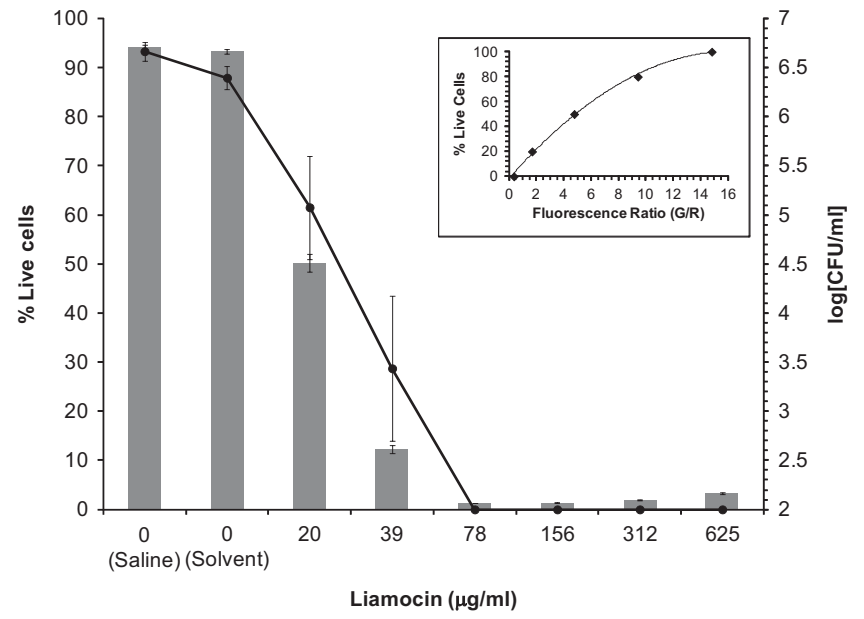

Figure 3 Viability of $S$. agalactiae following expsosure to liamocins. Bacterial viability following exposure to the indicated concentration of liamocins from A. pullulans NRRL 50380 was determined by a two-color fluorescence assay and by enumeration of surviving cells. Controls $\left(0 \mu \mathrm{g} \mathrm{ml}^{-1}\right.$ liamocins) include cells treated with saline and cells treated with 2-butanone:DMSO solvent $(1.25 \%(\mathrm{v} / \mathrm{v}))$. All assays were performed in triplicate. Bars indicate the percentage of live cells determined using the LIVE/DEAD BacLight Bacterial Viability Assay and using a standard curve plotting percent live cells versus the green:red fluorescence ratio (inset). The line indicates the bacterial density (log (CFU per $\mathrm{ml}$ )) of the surviving Streptococcus following $1 \mathrm{~h}$ exposure to the indicated concentration of liamocin. DMSO, dimethyl sulfoxide.

A. pullulans). In contrast, we observed that antibacterial activity of the liamocins shows specificity for Streptococcus over Enterococcus and Staphylococcus. Thus, despite sharing structural similarity (Figure 1), the liamocins appear to possess distinct and unique antibacterial activities compared with exophilin A. Halymecin F, a tetramer of DDA with a $\beta$-D-mannose situated at the C-3 position of the primary DDA group, was reported to have antimicrobial activity against several Gram-negative phytopathogens, including Agrobacterium tumefaciens, Ralstonia solanacearum and Xanothomonas euvesicatoria. ${ }^{10}$ Susceptibility testing against Gram-positive bacteria was not reported, however, and the available data do not allow for direct comparisons between halymecin $\mathrm{F}$ and liamocins.

Streptococcus is a genus of ubiquitous Gram-positive bacteria, some of which are etiologic agents of diseases in veterinary and clinical medicine. S. agalactiae and S. uberis are two commonly recognized species that cause mastitis in dairy cattle. ${ }^{11,12}$ S. mutans is associated with dental caries. ${ }^{13}$ S. suis is an emerging zoonotic pathogen associated with diseases like septicemia, pneumonia and endocarditis in pigs. ${ }^{14}$ In human clinical medicine, infections by species of Streptococcus cause numerous diseases including pharyngitis, impetigo, sepsis, toxic shock and necrotizing fasciitis. ${ }^{15}$
Some of these diseases may be controlled prophylactically with broad-spectrum antibiotics, but this is a controversial practice that may create reservoirs of antibiotic resistance and select for drugresistant microorganisms even among the non-target population. ${ }^{16}$ An antimicrobial agent that selectively targets a pathogen would be a desired feature of new interventions to treat and prevent infectious disease. In this initial investigation, only species of Streptococcus were susceptible to the antibacterial activity of liamocins. Furthermore, as liamocins are chemically different from any class of broad-spectrum antibiotic, one would not expect cross-resistance to any clinically important drugs. Thus, liamocins merit further attention as antimicrobial agents that target streptococcal pathogens.

\section{ACKNOWLEDGEMENTS}

Expert technical assistance for this study was provided by Melinda S. Nunnally and Eric Hoecker.

1 Singh, R. S., Saini, G. K. \& Kennedy, J. F. Pullulan: microbial sources, production and applications. Carbohydr. Polym. 73, 515-531 (2008).

2 Nagata, N., Nakahara, T. \& Tabuchi, T. Fermentative production of poly(beta-L-malic acid), a polyelectrolytic biopolyester, by Aureobasidium sp. Biosci. Biotech. Biochem. 57, 638-642 (1993).

3 Chi, Z. M. et al. Bioproducts from Aureobasidium pullulans, a biotechnologically important yeast. Appl. Microbiol. Biotechnol. 82, 793-804 (2009).

4 Manitchotpisit, P., Price, N. P., Leathers, T. D. \& Punnapayak, H. Heavy oils produced by Aureobasidium pullulans. Biotechnol. Lett. 33, 1151-1157 (2011).

5 Price, N. P. Manitchotpisit, P., Vermillion, K. E., Bowman, M. J. \& Leathers, T. D. Structural characterization of novel extracellular liamocins (mannitol oils) produced by Aureobasidium pullulans strain NRRL 50380. Carbohydr. Res. 370C, 24-32 (2013).

6 Isoda, H. \& Nakahara, T. Antiproliferative effect of polyol lipids, 3,5-dihydroxydecanoyl and 5-hydroxy-2-decenoyl esters of arabitol and mannitol on lung cancer cell line A549. J. Ferment. Bioeng. 84, 403-406 (1997).

7 Manitchotpisit, P. et al. Aureobasidium pullulans as a source of liamocins (heavy oils) with anticancer activity. World J. Microbiol. Biotechnol. 30, 2199-2204 (2014).

8 National Committee for Clinical Laboratory Standards. Performance Standards for Antimicrobial Disk and DIlution Susceptibility Tests for Bacteria Isolated from Animals. Approved standard, M31-A2 (Clinical Laboratory Standards Institute, Wayne, PA, USA, 2002)

9 Doshida, J., Hasegawa, H., Onuki, H., Shimidzu, N. \& Exophilin, A. a new antibiotic from a marine microorganism Exophiala pisciphila. J. Antibiot. 49, 1105-1109 (1996).

10 Le Dang, Q. et al. Antimicrobial activities of novel mannosyl lipids isolated from the biocontrol fungus Simplicillium lamellicola BCP against phytopathogenic bacteria. J. Agric. Food Chem. 62, 3363-3370 (2014).

11 Keefe, G. P. Streptococcus agalactiae mastitis: a review. Can. Vet. J. 38, 429-437 (1997).

12 Leigh, J. A. Streptococcus uberis: a permanent barrier to the control of bovine mastitis? Vet. J. 157, 225-238 (1999)

13 Hardie, J. M. \& Whiley, R. A. The genus streptococcus-oral in The Prokaryotes: A Handbook on the Biology of Bacteria (eds Dworkin, M. \& Falkow, S.) 76-107 (Springer, New York, NY, USA, 2006).

14 Lun, Z.-R., Wang, Q.-P., Chen, X.-G., Li, A.-X. \& Zhu, X.-Q. Streptococcus suis: an emerging zoonotic pathogen. Lancet Infect. Dis. 7, 201-209 (2007).

15 Cleary, P. C. \& Cheng, Q. Medically important beta-hemolytic streptococci in The Prokaryotes (ed. Dworkin, M.) 108-148 (Springer, New York, NY, USA, 2006).

16 Marshall, B. M. \& Levy, S. B. Food animals and antimicrobials: impacts on human health. Clin. Microbiol. Rev. 24, 718-733 (2011). 